\title{
Individual variability in growth rate and the timing of metamorphosis in yellowtail flounder Pleüronecies ferrugineus
}

\author{
Hugues P. Benoît ${ }^{1}$, Pierre Pepin ${ }^{2, *}$ \\ ${ }^{1}$ Department of Biology, Ocean Sciences Center, Memorial University of Newfoundland, St. John's, Newfoundland \\ A1C 5S7, Canada
}

${ }^{2}$ Science Branch, Northwest Atlantic Fisheries Center, Department of Fisheries and Oceans, PO Box 5667, St. John's,

Newfoundland A1C 5X1, Canada

\begin{abstract}
We studied individual variability in growth and development rates of yellowtail flounder Pleuronectes ferrugineus larvae, and its impact on age and size at metamorphosis. Larvae were reared from hatch to metamorphosis in 3 separate temperature treatments. Temperature influenced the location and distribution of individual transition ages and lengths of larvae reared in separate aquaria, mainly due to its role in determining the mean and range of individual growth rates. Individual metamorphic ages were negatively correlated with the average growth rate of larvae. Individual metamorphic lengths generally increased as mean individual growth rates increased, but higher mean growth also resulted in a wider diversity of lengths. In one of the treatments, the otoliths of the larvae were stained 3 times during the larval period using alizarin complexone, allowing us to reconstruct the growth history of individuals once they had metamorphosed. The body length that larvae had achieved by $2 \mathrm{wk}$ after hatch correlated negatively with the eventual age at metamorphosis. This relationship strengthened the nearer larvae were to metamorphosis. These results were attributed to serial autocorrelations in body length, and to a lesser extent growth rate, for individuals during the larval period. Overall these results suggest that events occurring early during ontogeny that affect the size and growth rates of larvae can impact life history transitions occurring several weeks or months later. As a result, variance in the timing of metamorphosis, which has been suggested as an important determinant of recruitment variability, may become established soon after hatching, and individual probabilities of survival to the juvenile stage may also be determined early on.
\end{abstract}

KEY WORDS: Timing of metamorphosis - Individual variability . Growth rate - Development rate . Otoliths - Temperature Pleuronectes ferrugineus

\section{INTRODUCTION}

During the early life history of the majority of fish, body size increases by orders of magnitude and adult characteristics are acquired within weeks or months. Meanwhile, eggs and larvae suffer high mortality rates (Dahlberg 1979, Sissenwine 1984). Recruitment begins to be roughly established at the late larval or early juvenile stages (Bradford 1992), when the biomass of

\footnotetext{
- Addressee for correspondence.

E-mail: pepin@athena.nwafc.nf.ca

the cohort ceases to decrease as a result of mortality, and begins to increase due to the growth of individuals (Beyer 1989, Houde 1997).

Which factors control recruitment in marine fishes is unclear (for reviews see Anderson 1988, Bailey \& Houde 1989, Cushing 1990, Leggett \& DeBlois 1994), however growth is important in determining overall survival. Differences in development and growth rates will affect the age-at-size, size-at-age and timing of early life history transitions (hatch, first feeding, yolk absorption, and metamorphosis) (Chambers et al. 1988, Bertram et al. 1997), and consequently may determine which individuals survive (Litvak \& Leggett 1992, Pepin et al. 
1992, Bell et al. 1995). Physiological (capacity for metabolism and catabolism) and environmental (temperature and food availability) factors affect transition size and age (Pepin 1991, Chambers \& Leggett 1992, 1996, Benoît 1999, Benoît \& Pepin 1999). Subtle differences in the timing of transitions, which often include large changes in behaviour, morphology, habitat and niche, can potentially create large changes in recruitment, with metamorphosis likely being the most important (Houde 1987, 1989b, Beyer 1989, Pepin \& Myers 1991. Bell et al. 1995).

Among species and populations, metamorphosis appears to be centered around a relatively fixed length, and transition age varies as a consequence of growth variation (Houde 1989a, Chambers \& Leggett 1992, Benoit 1999). Among species, population-level standard deviation in both age and length at metamorphosis increases exponentially with increases in their respective means (Benoit 1999). This suggests that the variance-generating mechanism is similar for all marine fishes regardless of their environment. A nearly identical power law (log-log mean-variance relationship) for metamorphic age and length further suggests that the two are not independent and that a 'target' transition length may not be an appropriate model for the timing of metamorphosis at the individual level. This is further supported by the observation that the strength of the metamorphic age-length relationship among individuals is directly proportional to the mean growth rate (Benoit 1999).

The role of the environment and its interaction with genetic and with non-genetic parental contributions (Chambers \& Leggett 1989, 1992, Benoit \& Pepin 1999) in determining the traits of individuals is generally poorly understood (e.g. Policansky 1982). This remains a problem because the majority of studies that have reared fish to metamorphosis under a variety of growing conditions fail to report the effects on the dispersion and distribution of traits within populations (e.g. Laurence 1975, Fonds 1979, Crawford 1984, Seikai et al. 1986). Understanding of the timing of metamorphosis at the individual level is essential because any selective mechanisms affecting survival and recruitment will ultimately operate at that level (Sharp 1987, Crowder et al. 1992, Rice et al. 1993).

In this study we quantify variation in age and size at metamorphosis in cohorts of yellowtail flounder Pleuronectes ferrugineus, and how this variation changes with the growing conditions. This direction follows from the idea that variance among individuals in the timing of metamorphosis is generated in a predictable and continuous manner, which is likely a result of individual variation in growth rates (Benoit 1999). To explore the idea that individual differences in larval growth trajectories are responsible for generating this variance, we also reconstruct the growth history of individuals, using the otoliths of metamorphosed fish. This allows us to determine when individual metamorphic traits (ages and sizes) become predictable by the size that larvae have achieved at an earlier date.

\section{MATERIALS AND METHODS}

Laboratory growth rate of larvae was manipulated by altering the temperature at which they were reared. We chose this approach rather than manipulating food availability in order to minimize the problems associated with food deprivation, which can result in competition among individuals and affect the physiological condition of larvae. Because the objective was to focus on how variation in growth rate during the larval period affects the timing of metamorphosis, eggs were reared to hatching under identical conditions $\left(8.4^{\circ} \mathrm{C}\right)$ and acclimatized to larval rearing temperatures after hatching.

Six, 225 I temperature-controlled water baths were used to create 3 treatments ( 2 baths per treatment) at nominal temperatures of $7^{\circ}\left(7.3 \pm 0.1^{\circ} \mathrm{C}\right.$, mean $\left.\pm \mathrm{SD}\right)$, $11^{\circ}\left(11.1 \pm 0.2^{\circ} \mathrm{C}\right)$ and $13^{\circ} \mathrm{C}\left(13.2 \pm 0.2^{\circ} \mathrm{C}\right)$ in which larvae were reared. Three or 4 (20 l, $20 \times 40 \times 25 \mathrm{~cm})$ aquaria were placed in each bath, for a total of 7 per temperature treatment. The outside walls of the aquaria were covered with black plastic to enhance the contrast of prey items for the larvae. Aquaria were filled with 181 of UV sterilized filtered seawater, and rearing conditions were kept static except for partial water changes ( 3 to 4 l) every $3 \mathrm{~d}$ during the egg stage and every $2 \mathrm{~d}$ during the larval stage. Dead eggs or larvae and detritus were siphoned from the bottom of the tanks during water changes. A 17 h light, 7 h dark photoperiod, representative of the natural photoperiod, was maintained using florescent lights hung approximately $1 \mathrm{~m}$ above the tanks. Temperatures were measured 3 times daily (at approximately 09:00, 13:00, and 17:00 h) using a digital thermometer, with $0.1^{\circ} \mathrm{C}$ accuracy. Temperatures varied little and the time series of temperature were deemed stationary (no long term trends or cycles) by visual inspection.

Yellowtail flounder eggs were obtained by stripping 6 females from a broodstock held for 2 to $3 \mathrm{yr}$ at the Ocean Sciences Center, Memorial University of Newfoundland (Canada). An equal contribution of eggs from each female was used to create a pool of mixed eggs. An aliquot of $4.0 \mathrm{ml}$ of eggs (yielding $~ 9140 \pm$ 340 eggs) was placed into each of 21 plastic vials $(20 \mathrm{ml})$ that were placed in an $8.4^{\circ} \mathrm{C}$ bath for $20 \mathrm{~min}$. After acclimation, fertilization was performed by mixing $0.2 \mathrm{ml}$ of mixed sperm (from 5 males) with the eggs. A mixture of gametes from several parents was used to 
randomize possible parental effects within and among treatments. Filtered seawater $(5 \mathrm{ml})$ was added to the vials in order to activate the sperm. After 2 min the fertilized eggs were gently poured into each of the 21 aquaria containing $18 \mathrm{l}$ of UV-sterilized filtered seawater.

Fertilized eggs were kept at $8.4 \pm 0.2^{\circ} \mathrm{C}$ throughout the incubation period. At the first water change, $100 \mathrm{mg} \mathrm{l}^{-1}$ of streptomycin and $60 \mathrm{mg} \mathrm{l}^{-1}$ of penicillin were added to the tanks. Eggs began hatching $6 \mathrm{~d}$ after fertilization, with median hatch occurring on Day 7 . On Day 9 after fertilization, 25 to 40 larvae from each aquaria were removed and measured for standard length under $250 \times$ magnification using an imaging system (Bioscan OPTIMAS ${ }^{\oplus} 4.10$ ) in order to establish the initial size distribution of larvae. To minimize disturbances, eggs and subsequently larvae were reared in the same aquaria. Beginning on Day 9, temperatures were slowly changed $\left(1^{\circ} \mathrm{C} \mathrm{d}^{-1}\right)$ to establish the 3 separate temperature treatments $\left(7,11\right.$, and $\left.13^{\circ} \mathrm{C}\right)$. In addition, $0.5 \mathrm{l}$ of golden algae Isochrysus sp. along with very light aeration were added to each aquarium. Aeration was subsequently increased $2 \mathrm{wk}$ later when a second antibiotic treatment was given to the larvae.

Larvae were fed ad libitum throughout the experiment. Cultured rotifers Brachionus sp. enriched with a mixture of powdered media and fresh algae were used throughout the experiment, although the size of rotifers added to the tanks depended on the size of the larvae. The average size of rotifers added to the aquaria was increased over the larval period by screening the rotifers using a nylon sieve. Rotifers measuring 40 to $120 \mu \mathrm{m}$ were added twice daily at densities of $4.0 \mathrm{ml}^{-1}$ beginning $1 \mathrm{wk}$ after hatching. Once average larval size reached 4 to $5 \mathrm{~mm}$, the mean rotifer size was increased by using only rotifers $>100 \mu \mathrm{m}$. For larvae between 5 to $6 \mathrm{~mm}$, rotifers were selected using a $150 \mathrm{\mu m}$ mesh. In addition to rotifers, brine shrimp Artemia sp. were added in densities of $2.0 \mathrm{ml}^{-1}$ once larvae reached an average of 7 to $8 \mathrm{~mm}$. Densities of brine shrimp were increased to $4.0 \mathrm{ml}^{-1}$, and rotifer densities decreased to $2.0 \mathrm{ml}^{-1}$ approximately $1 \mathrm{wk}$ later.

As larvae approached metamorphosis, individuals were examined every second day in order to find those that had metamorphosed. We defined metamorphosis as the point at which the iris of the migrating eye reached the neural crest and was visible from the other side of the body. This is commonly used as a standard method of scoring metamorphosis (e.g. Chambers \& Leggett 1987. Bertram et al. 1997). Metamorphosed individuals were removed from the aquaria, euthanized and preserved in $95 \%$ ethanol. To assess the effect of preservation on body measurements, standard length and maximum body depth (measured perpendicular to the longest axis of the fish) were measured on $>350$ live individuals under $64 \times$ magnification, prior to preservation. These individuals were remeasured 3 to 4 mo later (when all metamorphosed fish were measured). Age at metamorphosis is defined as the number of days between scoring a fish as a metamorph and modal. hatching date.

Experiments were terminated prior to metamorphosis for 4 fish at $7^{\circ} \mathrm{C}$. The larvae were nonetheless measured and their development was roughly srored by the position of their migrating eye. These individuals were included in some of the analyses that are able to accommodate such data (see 'Analyses' section for details\}.

Individual growth histories. Given the inability to tag individual larvae, and the difficulty in rearing individuals in isolation to make repeated length measurements (see Bertram et al. 1997), we chose to utilize the relationship between body length and otolith diameter of common age fish to reconstruct the growth history of individual fish. In order to alleviate problems associated with non-daily deposition of otolith rings (e.g. Sogard 1991, Szedlmayer \& Able 1992) and variation in the otolith:somatic growth relationship (Campana 1990), we marked larval otoliths at specific time intervals in the $11^{\circ} \mathrm{C}$ treatment. We could then confidently measure the diameter of the otolith at that time and backcalculate the size of the fish. We used a solution of seawater and alizarin complexone $\left(\mathrm{C}_{19} \mathrm{H}_{15} \mathrm{NO}_{8} \mathrm{H}_{2} \mathrm{O}\right)$, which is incorporated into the new otolith growth increments and fluoresces under UV light. Otoliths were marked on the 18th, 30th and 43rd day of the larvae period in 3 of the 7 tanks in the $11^{\circ} \mathrm{C}$ treatment (Table 1).

To mark the larval otoliths, the water volume in the 3 aquaria was reduced to 51 . Four liters of a $112.5 \mathrm{mg} \mathrm{l}^{-1}$ alizarin solution (prepared by diluting $1.35 \mathrm{~g}$ of alizarin in $270 \mathrm{ml}$ of distilled water and topping up with $11.7 \mathrm{l}$ of seawater containing algae and rotifers) was gently poured into each aquarium to yield a final concentration of $50 \mathrm{mg} \mathrm{l}^{-1}$. Immersion of larvae lasted $16 \mathrm{~h}$, after which they were transferred using a nylon filter to aquaria containing filtered seawater and algae. Overall the staining process and subsequent transfer of larvae to clean water resulted in very low mortality ( $<3$ individuals per tank per staining period).

These aquaria were checked for metamorphosing larvae in the same manner as unmarked treatments, and individuals were preserved similarly. After measuring for preserved length, left and right otoliths (sagitta, lapilli, and asteriscii) were removed using a dissecting scope and mounted on microscope slides using thermoplastic cement. Lapilli were viewed under $1000 \times$ magnification using $365 \mathrm{~nm}$ UV light and a wide band interference blue filter. The diameter of each fluorescent ring and the total diameter of the otolith were measured along the longest axis using an ocular micro- 
Table 1. Pleuronectes ferrugineus. Number of larvae (n) surviving to metamorphosis and larvae (c) that were removed from the experiment prior to metamorphosis in each tank at each temperature, along with the $( \pm \mathrm{SD})$ mean ages and lengths at metamorphosis, and $(\tau)$ Kendall's tau nonparametric correlation between age and length. All values of $t$ were statistically significant $(p<0.05)$ except where indicated (ns). Note that no larvae survived in Tanks 6 and 7 at $7^{\circ} \mathrm{C}$, and larvae were only available from 1 tank in the $13^{\circ} \mathrm{C}$ treatment. $\cdot$ tanks at $11^{\circ} \mathrm{C}$ in which otoliths were stained

\begin{tabular}{|c|c|c|c|c|c|c|c|c|}
\hline $\begin{array}{l}\text { Temp. } \\
\left({ }^{\circ} \mathrm{C}\right)\end{array}$ & Tank & $n$ & C & $\begin{array}{c}\text { Mean age } \\
\text { (days) }\end{array}$ & $\mathrm{SD}$ & $\begin{array}{c}\text { Mean length } \\
\text { (mm) }\end{array}$ & SD & $\underset{\tau}{\text { Kendall's }}$ \\
\hline \multirow[t]{5}{*}{7} & 1 & 25 & 2 & 118.0 & 14.5 & 17.1 & 2.3 & -0.41 \\
\hline & 2 & 84 & & 118.0 & 10.7 & 17.2 & 2.0 & 0.24 \\
\hline & 3 & 17 & 1 & 121.0 & 10.6 & 15.8 & 1.7 & $-0.09 \mathrm{~ns}$ \\
\hline & 4 & 13 & & 121.8 & 16.0 & 15.3 & 2.4 & -0.58 \\
\hline & 5 & 4 & 1 & 110.0 & 8.7 & 16.2 & 1.5 & $-0.91 \mathrm{~ns}$ \\
\hline \multirow[t]{7}{*}{11} & 1 & 195 & & 111.9 & 16.6 & 16.9 & 2.3 & 0.52 \\
\hline & $2^{\circ}$ & 62 & & 81.2 & 9.5 & 18.0 & 2.2 & 0.23 \\
\hline & 3 & 161 & & 97.5 & 15.7 & 16.4 & 2.0 & 0.32 \\
\hline & $4^{\circ}$ & 104 & & 86.6 & 12.0 & 18.0 & 2.1 & 0.21 \\
\hline & 5 & 36 & & 86.0 & 15.0 & 19.0 & 2.8 & $-0.28 \mathrm{~ns}$ \\
\hline & 6 & 167 & & 93.8 & 13.8 & 17.0 & 2.3 & 0.41 \\
\hline & $7^{\circ}$ & 41 & & 75.1 & 10.2 & 19.7 & 3.2 & $0.16 \mathrm{~ns}$ \\
\hline 13 & 1 & 71 & & 75.4 & 11.9 & 18.9 & 2.2 & $-0.05 \mathrm{~ns}$ \\
\hline
\end{tabular}

increase in otolith diameter $(\mu \mathrm{m})$ divided by the time interval over which growth was measured. Growth rate from hatch to Day 18 was calculated assuming a constant diameter of $11 \mu \mathrm{m}$ at hatch (estimated from the diameter:length relationship for the youngest larvae, and assuming a mean hatch length of $3.2 \mathrm{~mm}$ ). Analyses involving otolith diameters and growth rates were performed using rank correlations (which are independent of absolute magnitude).

Analyses. Covariance between age and length at metamorphosis among individuals was analyzed using nonparametric correlation analysis (Kendall's $\tau$ ), which assumes a monotonic relationship between variables, in addition to segmented regression analysis that fits a biphasic regression to the data. A nonlinear, segmented fitting algorithm (Wilkinson 1992) was used to test the working assumption that the data can be represented by 2 linear segments, differing in slope. In particular, we were interested in determining non-arbitrarily a point at which age and length at metamorphosis go from being unmeter. Fluorescent bands did not appear on the asteriscii, likely because these form later during ontogeny (Secor et al. 1992). Sagittae had large accessory primordia that appeared to form once metamorphosis began (H.P.B. unpubl.), and that would have required substantial polishing in order to measure the bands.

In order to establish the relationship between otolith diameter and larval length for each staining period, 10 to 15 larvae were removed from each of the 'stained' tanks the day following each marking and were measured and preserved individually in ethanol. The otoliths from these larvae (lapilli and sagittae) were later removed, mounted and measured as described above. Unfortunately the larvae that were taken for the 18 and $30 \mathrm{~d}$ staining periods were preserved in ethanol that was too weak $(<80 \%)$ and consequently became too acidic to properly preserve the otoliths. We later obtained 11 and $20 \mathrm{~d}$ old larvae from 2 separate general. rearing stocks held at the Ocean Sciences Center (Memorial University of Newfoundland) that had similar mean lengths as the larvae from the experiment at 18 and $30 \mathrm{~d}$ respectively in order to establish otolith diameter:body length relationships. There is the potential that different growth rates of these larvae would result in differences in the slope and intercept of the relationship (Reznick et al. 1989, Campana 1990). In order to avoid introducing any biases in our data, all analyses were performed using otolith diameters rather than back-calculated body lengths. Growth rates were calculated as the correlated to being positively related. The model used was of the form:

$$
\begin{array}{ll}
\text { length } & \left.=B_{0}+B_{1} \text { (age }\right), \quad \text { when age } \leq \text { BREAK } \\
\text { length } \left.=B_{0}+\left(B_{1}+B_{2}\right) \text { (age }\right), & \text { when age }>\text { BREAK }
\end{array}
$$

where $B_{0}$ is the intercept ( $\left.\mathrm{mm}\right), B_{1}$ is the slope of the first segment $\left(\mathrm{mm} \mathrm{d}^{-1}\right), B_{2}$ is the difference in slope between the first and second segment (i.e. the slope of the second segment $=B_{1}+B_{2}$ ), and BREAK (days) is the inflection between the first and second segments. Confidence intervals (95\%) are reported for each parameter. We acknowledge that the relationships to which we fit the lines are continuous, but as mentioned previously, we were most interested in determining the location of a possible break point, rather than testing ing the functional relationship in detail. We only fit biphasic regressions to data from those tanks that visually showed a change in age-length correlation over time. Robustness of parameter estimates was tested by varying the initial values used in the estimation.

The analyses of the frequency distributions of both age and length at metamorphosis were performed using event analysis (Cox \& Oakes 1984, Chambers \& Leggett 1989) in which the entire distribution of ages or lengths in a population is used to describe the timing of metamorphosis. Event analysis fits a theoretical statistical distribution to the observed frequency data, and uses the parameters that describe that probability distribution (its shape and position) to test for differhypotheses on the magnitudes of the slopes or describ- 
ences among different observed frequency distribution. Using this technique, one simultaneously tests for differences in the mean, dispersion and distribution of metamorphic ages and lengths among treatments (i.e. compares all of the individuals in the population, not just the average ones). This is one of the advantages of this technique over standard parametric analyses, which compare average responses and use variance as a description of error, as information from all individuals in the population is retained at its original level, rather than amalgamating it in the estimation of a mean. A second advantage is that this type of analysis allows the incorporation of data on individuals that were removed from the experiment prior to undergoing the event (termed 'censored' individuals). This reduces potential biases because until the individuals were removed from the experiment they were at 'risk' of undergoing the event and consequently they contribute to the dispersion. For a more detailed explanation, as well as examples of the application of event analysis to the study of fish early life history, see Chambers \& Leggett (1989) and Pepin et al. (1997).

A Weibull distribution, which is described by 2 parameters, was used to model individual ages and lengths at metamorphosis as it provided the best log-likelihood fit to the data. The survival function of the Weibull distribution is defined as

$$
\mathrm{S}(t)=\exp \left[-(t / \alpha)^{\gamma}\right]
$$

where $t$ is the timing of the transition (i.e. individual age or length at metamorphosis), $\alpha$ is a scale parameter in units of time (days) or length $(\mathrm{mm})$, and $\gamma$ is a dimensionless shape parameter. The survival function is the complement of the cumulative frequency distribution $[F(t)]$ of metamorphic ages and lengths [i.e. $S(t)=$ $1-F(t)$ ]. Eq (2) can be modified into an accelerated failure time model by including ' $n$ ' treatment variables (e.g. temperature, fish density, etc), described by a vector $v^{\prime}=\left(v_{1}, v_{2}, \ldots, v_{n}\right)$, such that

$$
S(t ; v)=\exp \left[-\{t / \alpha)^{\gamma} \exp ^{\nu^{\prime} \beta}\right]
$$

assuming that the elements of $v$ interact through a linear function, $v^{\prime} \beta$, where $\beta_{i}$ are parameters to be estimated.

The analysis uses log-transformed ages or lengths, which yields the standard extreme value distribution that is multiplied by a scale factor (analogous to the variance of a normal distribution), and translated by a location parameter ( mean). Observations of individual event times are related to explanatory variables in a regression model, as

$$
\mathrm{Y}=\mathrm{V} \beta+\sigma \varepsilon
$$

where $\mathrm{Y}$ is the vector of $\log$-transformed ages or lengths at metamorphosis, $V$ is the matrix of explana- tory variables, $\beta$ is the vector of coefficients to be estimated, $\sigma$ is the scale parameter to be estimated, and $\varepsilon$ is the extreme value distribution in the case of the Weibull distribution. Sigma $(\sigma)$ is the inverse of the shape parameter $\gamma$ in the Weibull distribution, and $\beta_{1}$, an estimate of the intercept, is the location parameter of the extreme value distribution [i.e. $=\log (\alpha)]$. Finally, $\varepsilon$ is a random error vector from the assumed extreme value distribution. In Eq. (4) the explanatory variables act multiplicatively on individual ages/sizes, resulting in acceleration of event timing. Parameters were estimated using iterative maximum likelihood methods.

\section{RESULTS}

Overall, survival was variable across aquaria and temperatures (Table 1). As a result only 5 tanks were available for analysis at $7^{\circ} \mathrm{C}$, with generally low numbers except in 1 tank. A.t $11^{\circ} \mathrm{C}$ survival was variable across replicates but sample sizes in all aquaria were high. Due to an accident in the $13^{\circ} \mathrm{C}$ treatment 2 mo into the study, all but 1 replicate were lost. As a result of this variability we will include all of the aquaria in a general analysis of temperature and growth effects, but we will subsequently focus on the $11^{\circ} \mathrm{C}$ treatment to assess sources of experimental error among replicates.

\section{Effects of preservation}

Preservation in $95 \%$ ethanol caused substantial shrinkage of the metamorphosing larvae. Preservation effects were estimated by fitting an asymptotic relationship to data from 371 fish, where

$$
\text { preserved length }=\beta_{0}\left(1-\exp \left[-\beta_{1} \text { fresh length }\right]\right) \text { (5) }
$$

where $\beta_{0}$ is the asymptote of the curve, and $\beta_{1}$ determines the rate at which the asymptote is reached. This model performed very well $\left(R^{2}=0.96, p<0.0001\right)$, with estimated parameter values and associated asymptotic standard errors of $\beta_{\circ}=161.03 \pm 26.14$ and $\beta_{1}=0.0061 \pm 0.0011$ (due to the high degree of explained variance we do not present a plot of these data). Preservation effects were also estimated for measurements of body depth $\left(\beta_{0}=43.47 \pm 6.93\right.$, $\beta_{1}=0.025 \pm 0.004, R^{2}=0.89, p<0.0001$ ). The high degree of explained variance suggests that differential shrinkage of larvae (resulting in changes in the size rank of larvae) did not significantly affect our results regarding the statistical distributions of metamorphic lengths. All subsequent analyses have been performed using preserved lengths as the unit of study. 


\section{Covariation between age and length at metamorphosis}

Mean age and length at metamorphosis were negatively correlated across tanks ( $\mathrm{n}=13, \mathrm{r}=-0.85$, $p<0.0001$ ) (Fig. 1). The relationship is independent of temperature, suggesting that the average response of a population of larvae is a result of the mean growth rate. Slower growth results in increased age and decreased length at metamorphosis.

Within aquaria the relationship between age and length is complex (Fig. 2). In general there is little or no covariation between age and length in treatments with survivor numbers less than 85 ind $\operatorname{tank}^{-1}$ (Table 1). Some exceptions occurred for tanks at $7^{\circ} \mathrm{C}$ but these appear to be driven by relatively few older larvae (>140 d of age)(Fig. 2). In contrast, a positive covariance develops in tanks with higher densities (Fig. 2, Table 2). In Tanks 1, 3, 4, and 6 of the $11^{\circ} \mathrm{C}$ treatment a positive correlation between age and length at metamorphosis appears after an average of 89.0 to $97.9 \mathrm{~d}$, as determined by segmented regression analysis (Table 2). By that time almost all of the larvae in the lower density tanks (Tanks 2, 5 and 7) had undergone metamorphosis, and consequently do not show this tendency.

\section{Age at metamorphosis}

It is difficult to describe the distributions for the raw data on metamorphic age beyond the mean and variance (Fig. 2). Nonetheless, Weibull distributions fit reasonably well to observed distributions. Event analysis reveals that age at metamorphosis differed significantly among temperature treatments (Table 3), and a

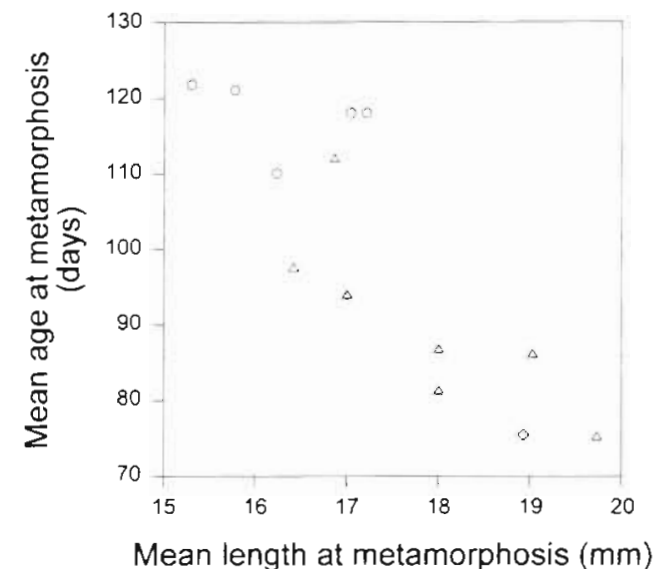

Fig. 1. Pleuronectes ferrugineus. Relationship between mean age and length at metamorphosis in individual aquaria (temperature and replicate). (o) $7^{\circ} \mathrm{C},(\Delta) 1.1^{\circ} \mathrm{C}$ and $(0) 13^{\circ} \mathrm{C}$

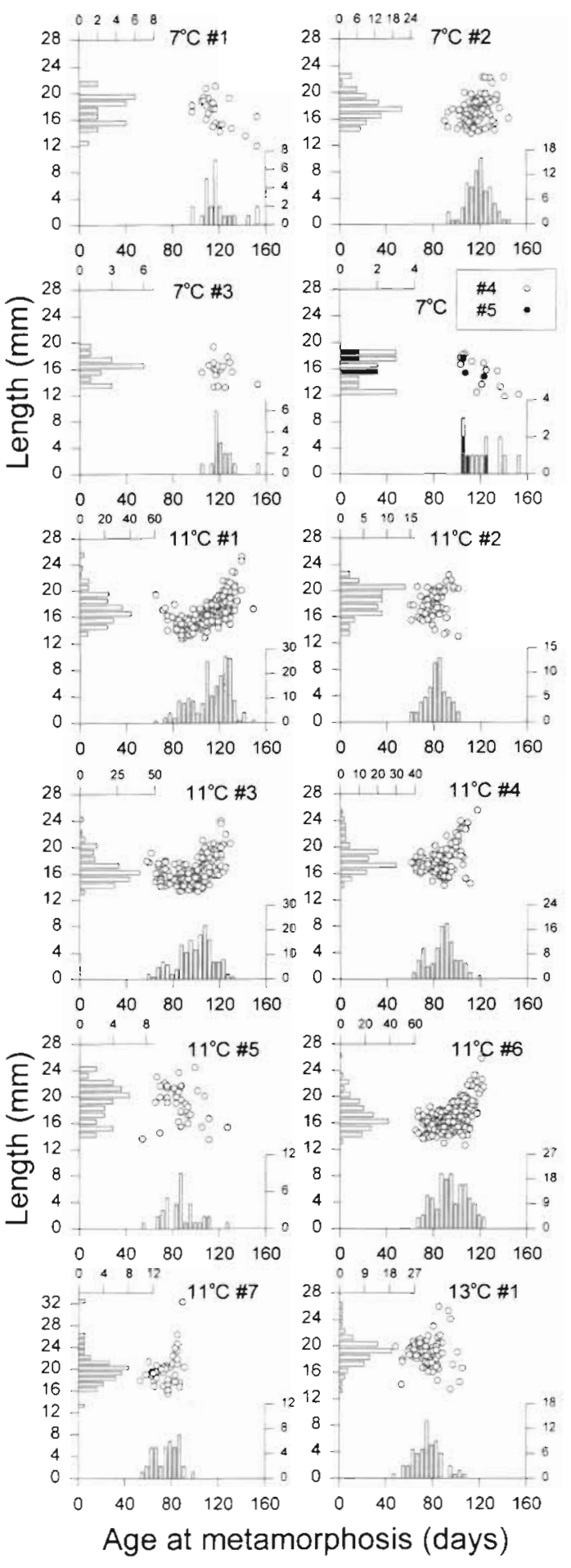

Fig. 2. Pleuronectes ferrugineus. Ages and lengths at metamorphosis for each aquaria of laboratory-reared yellowtail flounder. Each point in the bivariate plots represents the response of 1 individual (see Table 1 for sample sizes). Frequency distributions are for the univariate responses of age and length. The scales for the distributions can be found on the secondary $x$ - and $y$-axes for age and length respectively Note that Tanks 4 and 5 from the $7^{\circ} \mathrm{C}$ treatment are combined in a single panel, with additive frequency bars 
Table 2. Pleuronectes ferrugineus. Results of segmented regression analyses on individual measures of age and length at metamorphosis for those tanks that display a biphasic relationship. Parameter estimates are given with lower and upper confidence intervals. See 'Materials and methods' for details regarding the analyses

\begin{tabular}{|cccccccc|}
\hline Temp. $\left({ }^{\circ} \mathrm{C}\right.$ ) & Tank & df & $\mathrm{R}^{2}$ (corrected) & Intercept & Slope 1 & Slope 2 & Break \\
\hline 11 & 1 & 4,191 & 0.53 & $22.4(17.3,27.5)$ & $-0.08(-0.14,-0.03)$ & $0.24(0.17,0.30)$ & $97.9(93.6,102.1)$ \\
& 3 & 4,157 & 0.41 & $19.2(16.3,22.2)$ & $-0.05(-0.08,-0.01)$ & $0.21(0.16,0.27)$ & $95.9(91.9,99.9)$ \\
& 4 & 4,100 & 0.29 & $18.6(14.7,22.5)$ & $-0.02(-0.06 .0 .03)$ & $0.22(0.12,0.31)$ & $89.0(87.9,90.1)$ \\
& 6 & 4,163 & 0.45 & $13.6(10.1,17.1)$ & $0.03(-0.01,0.07)$ & $0.17(0.09,0.24)$ & $96.2(90.3,102.1)$ \\
\hline
\end{tabular}

Table 3. Pleuronectes ferrugineus. Fit to the accelerated failure model (Eq. 4) for log-transformed metamorphic ages and lengths

\begin{tabular}{|c|c|c|c|c|c|c|c|c|c|c|}
\hline & \multirow{2}{*}{$\begin{array}{l}\text { Temp } \\
\left({ }^{\circ} \mathrm{C}\right)\end{array}$} & \multicolumn{5}{|c|}{ Age at metamorphosis } & \multicolumn{4}{|c|}{ Length at metamorphosis } \\
\hline & & $\mathrm{df}$ & Estimate & SE & $\chi^{2}$ & $\mathrm{p}$ & Estimate & SE & $\chi^{\frac{1}{2}}$ & $\mathrm{p}$ \\
\hline Intercept & & 1 & 4.27 & 0.02 & 57039.9 & $<0.0001$ & 3.04 & 0.02 & 28619.2 & $<0.0001$ \\
\hline \multirow[t]{3}{*}{ Temp } & 7 & 1 & 0.460 & 0.021 & 498.0 & $<0.0001$ & -0.116 & 0.021 & 32.0 & $<0.0001$ \\
\hline & 11 & 1 & 0.101 & 0.026 & 29.6 & $<0.0001$ & -0.013 & 0.019 & 0.50 & 0.48 \\
\hline & 13 & 1 & 0 & 0 & - & - & 0 & 0 & & - \\
\hline Density & & 1 & $1.78 \times 10^{-3}$ & $0.90 \times 10^{-3}$ & 416.0 & $<0.0001$ & $-0.83 \times 10^{-3}$ & $0.90 \times 10^{-5}$ & 86.2 & $<0.0001$ \\
\hline Scale & & 1 & 0.140 & 0.003 & & & 0.141 & 0.003 & & \\
\hline Log-likelil & bod: & & & 441.1 & & & & 503.5 & & \\
\hline
\end{tabular}

significant effect of fish density was also detected. Age at metamorphosis increased as temperature decreased and as the density of fish at metamorphosis increased.

Variance in age at metamorphosis was not significantly related to average age, as determined by a power law, or log-log linear regression $\left(F_{1,12}=2.13\right.$, $\left.\mathrm{p}>0.1, \mathrm{R}^{2}=0.15\right)$, contrary to the findings of Benoit (1999) for other species. As noted previously, event analysis had suggested that larval density affected age dispersion, consequently its effect was added to the linear model relating mean and variance. Although this increased the explained variance to $48 \%$, all parameters were not statistically significant at $\alpha=0.05$. Density did however significantly affect the skewness of the age distribution for untransformed data ( $\mathrm{r}=$ $-0.73, \mathrm{p}<0.007, \mathrm{n}=12$ ), with lower density populations showing positive skewness and high densities resulting in slight negative skewness (Fig. 3).

\section{Length at metamorphosis}

Event analysis shows that length at metamorphosis differed significantly among the $7^{\circ} \mathrm{C}$ and the 11 and $13^{\circ} \mathrm{C}$ treatments, but the latter two did not differ significantly from one another (Table 3). A significant effect of larval density was also detected. Overall, length at metamorphosis decreased with decreasing temperature and with increasing density. Given the strong density effect at $11^{\circ} \mathrm{C}$, we explored the impact of larval density on the length distributions within each temperature treatment. Furthermore we incorporated the covariance with age to explore its effect on shaping the distributions of length within each treatment, as the segmented regression analysis had shown that this effect was not constant across aquaria and temperatures. The intercept, or location of the distributions, increased as temperature increased (Table 4). Age did not significantly affect the distribution of sizes at $7^{\circ} \mathrm{C}$, but had a significant impact in the other 2 treatments, although the effect at $13^{\circ} \mathrm{C}$ is largely due to a few individuals (Fig. 2). The effect at $11^{\circ} \mathrm{C}$ reflects the unequal distribution of ages among lengths (largest individuals also oldest) at higher densities. Density effects were marginally insignificant at $7^{\circ} \mathrm{C}$ but highly significant at $11^{\circ} \mathrm{C}$ (Table 4 ). Density effects at $11^{\circ} \mathrm{C}$ were largely

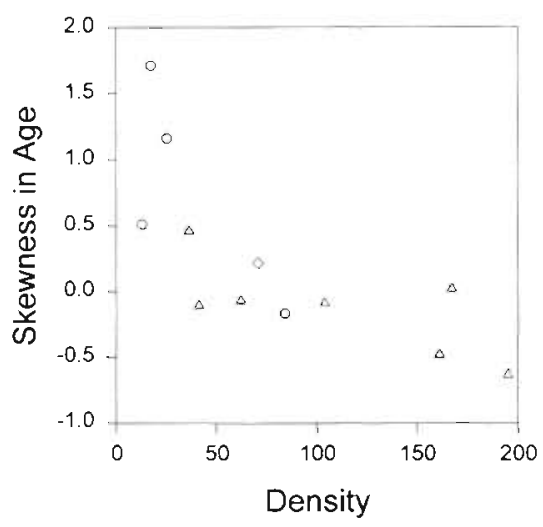

Fig. 3. Pleuronectes ferrugineus. Effect of fish density on the skewness of the metamorphic age distribution in each tank. (o) $7^{\circ} \mathrm{C},(\Delta) 11^{\circ} \mathrm{C}$ and $(0) 13^{\circ} \mathrm{C}$ 
Table 4. Pleuronectes ferrugineus. Temperature-specific fit of the accelerated failure model (Eq. 4) to log-transformed metamorphic lengths, including the effects of age and density

\begin{tabular}{|c|c|c|c|c|}
\hline & $\begin{array}{l}\text { Parameter } \\
\text { estimate }\end{array}$ & $\mathrm{SE}$ & Chi-sq & $\mathrm{p}$ \\
\hline \multicolumn{5}{|l|}{$7^{\circ} \mathrm{C}$} \\
\hline Intercept & 2.67 & 0.11 & 602 & $<0.0001$ \\
\hline Age $\left(\times 10^{-3}\right)$ & 1.50 & 0.98 & 2.36 & $>0.1$ \\
\hline Density $\left(\times 10^{-3}\right\}$ & 0.61 & 0.327 & 3.48 & 0.062 \\
\hline Scale & 0.11 & 0.007 & & \\
\hline \multicolumn{5}{|l|}{$11^{\circ} \mathrm{C}$} \\
\hline Intercept & 2.74 & 0.02 & 18071 & $<0.0001$ \\
\hline Age $\left(\times 10^{-3}\right)$ & 4.55 & 0.23 & 386 & $<0.0001$ \\
\hline Density $\left(\times 10^{-3}\right)$ & -1.97 & 0.09 & 457 & $<0.0001$ \\
\hline Scale & 0.12 & 0.003 & & \\
\hline \multicolumn{5}{|l|}{$13^{\circ} \mathrm{C}$} \\
\hline Intercept & 2.75 & 0.085 & 1036 & $<0.0001$ \\
\hline Age $\left(\times 10^{-3}\right)$ & 3.26 & 1.13 & 8.29 & $<0.005$ \\
\hline Scale & 0.11 & 0.010 & & \\
\hline
\end{tabular}

manifested in a shifting of the mode of the distribution towards smaller sizes as density increased, as the absolute range of sizes was relatively constant across aquaria (Fig. 2). The effect of density on the mode of the distribution contributed to a significant positive relationship between density and skewness in length $(\mathrm{r}=0.84, \mathrm{p}<0.0001, \mathrm{n}=13)$ when all tanks/temperatures are considered (Fig. 4).

A statistically significant power law, relating logtransformed mean length and its associated variance, explained $52.7 \%$ of the variance in the dispersion of lengths (slope $=3.66 \pm 1.00(\mathrm{SE})$, intercept $=-3.85 \pm 1.24$, $\left.F_{1.10}=13.38, \mathrm{p}<0.005\right)$. Larval density had no significant effect on dispersion $\left(F_{1,10}=1.90, \mathrm{p}=0.20\right)$. This result further supports the observation that density affects mainly the skewness of the distribution of indi-

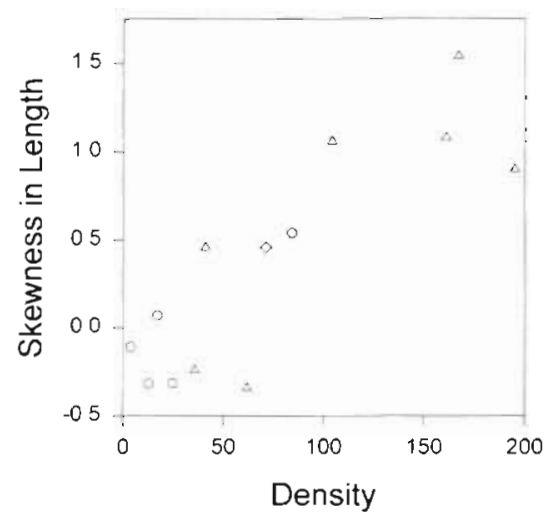

Fig. 4. Pleuronectes ferrugineus. Effect of fish density on the skewness of the metamorphic length distribution in each tank. (o) $7^{\circ} \mathrm{C},(\Delta) 11^{\circ} \mathrm{C}$ and (o) $13^{\circ} \mathrm{C}$ vidual characters, without greatly affecting the range and dispersion of the lengths in a population.

\section{Body depth}

Length of metamorphosing larvae explained $87.6 \%$ of the variance in body depth in a log-log regression $\left(F_{1,1029}=2578, \mathrm{p}<0.0001\right)$. Expanding the linear model, we found a significant tank (nested in temperature $)$ effect $\left(F_{16,1003}=15.22, \mathrm{p}<0.0001\right)$, although both temperature and length $x$ temperature interaction effects were not significant $\left(F_{3,1003}=1.16, p>0.3\right.$, and $F_{3,1003}=1.93, p>0.1$, respectively). Despite the significant tank effect, the larger model increased the explained variance by only $3.6 \%$. This result means that overall, body depth (a proxy for the mass of individuals) at metamorphosis did not significantly vary independently of metamorphic length. Furthermore, the lack of significant interactions between body depth and temperature suggests that mass scales to length in the same manner under different growth regimes (i.e. individuals are not growing in length at the expense of body mass).

\section{Otolith reconstruction}

Length corresponds reliably to otolith diameter in common aged fish as small as about $5 \mathrm{~mm}$ (Fig 5). Although the larvae from the 2 youngest groups were grown under different conditions than the experimental fish, they nonetheless fit in with the overall trend of increasing otolith diameter with increasing body size. This allows us to use otolith diameters for 18 and $30 \mathrm{~d}$ old experimental larvae as indices of larval length (i.e. we can assume that a relatively larger otolith came from a larger larvae, but we cannot estimate a length precisely). Overall the correspondence between otolith diameter and body length improves as mean length and the range of lengths increases, as suggested by decreasing standard errors and increasing explained variance (Fig. 5, Table 5). The relationship at metamorphosis is weaker (Table 5), likely due to the diversity of ages-at-length, which can affect the otolith diameter:body length. relationship (Reznick et al. 1989, Campana 1990).

The relationship between measured diameters for left and right otoliths of experimental fish improved as the larvae aged and grew (Table 5). For $18 \mathrm{~d}$ old larvae, the diameter of the left otolith explained $64 \%$ of the variance in that of the right, which is likely a result of measurement error for small otoliths, in addition to the limited range of diameters being compared Explained variance increased as did the slope of the 


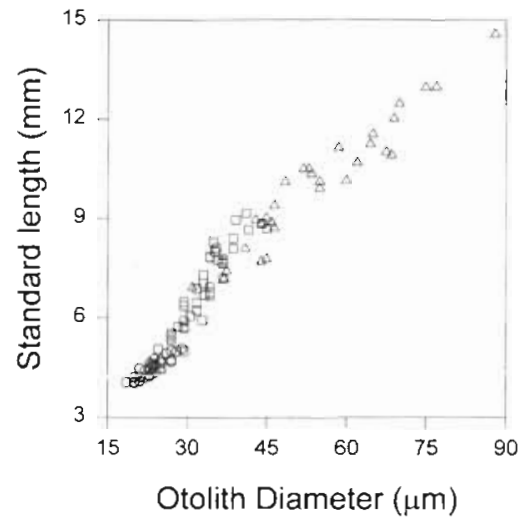

Fig. 5. Relationship between otolith diameter and standard body length for larvae from different age classes. (0) 11 , (a) 20 and $(\Delta) 43$ d old larvae

relationship (tending towards a value of 1 ) for 30 and $43 \mathrm{~d}$ old larvae. Explained variance decreased slightly for the total diameter measured at metamorphosis, partly due to increasing deformities on the lapilli caused by the formation of small primordia (H.P.B. unpubl. dataj. For the analyses that follow, 1 of the otoliths was randomly chosen when measurements were made on both right and left otoliths.

A significant negative correlation between otolith diameter ( body length) and age at metamorphosis was detected for all aquaria at $18 \mathrm{~d}$ (Fig. 6. Table 6). The correlation improved as larvae aged, and by $43 \mathrm{~d}$ otolith diameter explained about 38 to $74 \%$ of the variance in age at metamorphosis, a result similar to that found by Bertram et al. (1997). However, as we noted before, the relationship between age and length at

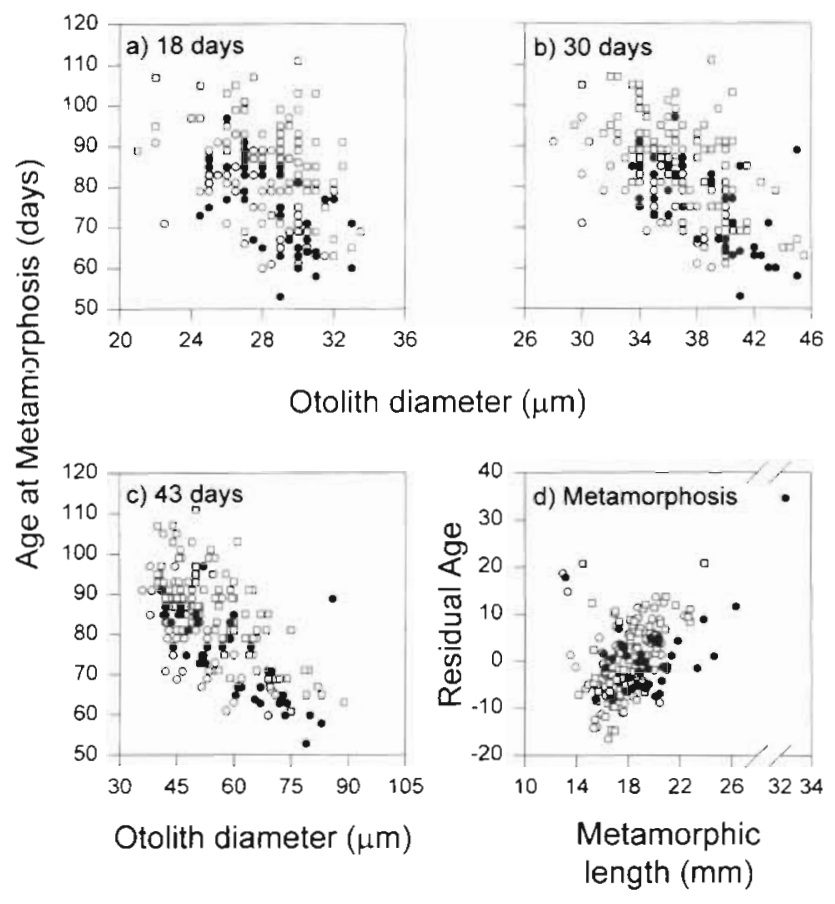

Fig. 6. Relationship between age at metamorphosis and otolith diameter at (a) 18, (b) 30, and (c) 43 d of age, for Tanks (o) 2 , (a) 4 and (-) 7 , at $11^{\circ} \mathrm{C}$. (d) relationship between the residuals from panel (c) and length at metamorphosis. Residuals were calculated from regressions relating otolith diameter at $43 \mathrm{~d}$ and age at metamorphosis for each tank

metamorphosis was weak in Tanks 2, 4 and 7 (Fig. 2). To gain a better understanding of this result, we correlated the residuals from the age versus size at a $43 \mathrm{~d}$ relationship, to the size at metamorphosis (Fig. 6d). By doing so we effectively separate age at metamorphosis

Table 5. Pleuronectes ferrugineus. Regressions relating otolith diameter and standard length for common aged larvae and larvae at metamorphosis, and regressions comparing the diameters of left and right otoliths at each staining period and at metamorphosis

\begin{tabular}{|c|c|c|c|c|c|c|}
\hline \multicolumn{7}{|c|}{ Regressions for back-calculation of length (SL $=$ intercept + slope $\times$ otolith diameter) } \\
\hline & N & Mean length (mm) & Range (mm) & $\mathrm{R}^{2}$ & Intercept (SE) & Slope (SE) \\
\hline $11 \mathrm{~d} \mathrm{old}^{\mathrm{a}}$ & 28 & 4.49 & $4.02-5.07$ & 0.77 & $2.08(0.26)$ & $0.10(0.01)$ \\
\hline $20 \mathrm{~d} \mathrm{old}^{\mathrm{d}}$ & 40 & 7.04 & $4.99-9.17$ & 0.84 & $-0.64(0.54)$ & $0.23(0.02)$ \\
\hline $43 \mathrm{~d}$ old (stained) & 30 & 10.07 & $6.92-14.6$ & 0.93 & $2.74(0.40)$ & $0.13(0.01)$ \\
\hline At metamorphosis & 186 & 18.22 & $12.9-32.4$ & 0.59 & $3.20(0.93)$ & $0.10(0.01)$ \\
\hline \multicolumn{7}{|c|}{ Comparison of right and left otoliths (right diameter $=$ intercept + slope $\times$ left diameter) } \\
\hline & $N$ & Mean diameter ( $\mathrm{mm}$ ) & Range $(\mathrm{mm})$ & $\mathrm{R}^{2}$ & Intercept $(S E)$ & Slope (SE) \\
\hline $18 \mathrm{~d}$ old (stained) & 117 & 28.31 & $21.0-33.5$ & 0.64 & $8.03(1.45)$ & $0.72(0.05)$ \\
\hline 30 d old (stained) & 117 & 37.06 & $28.0-45.5$ & 0.84 & $4.23(1.39)$ & $0.89(0.04)$ \\
\hline $43 \mathrm{~d}$ old (stained) & 117 & 54.85 & $36.0-89.0$ & 0.97 & $1.39(0.93)$ & $0.98(0.02)$ \\
\hline At metamorphosis & 117 & 146.82 & $104.6-230.2$ & 0.91 & $3.31(4.09)$ & $0.97(0.03)$ \\
\hline
\end{tabular}


Table 6. Pleuronectes ferrugineus. Spearman rank correlations (and their statistical significance) for measurements made on otoliths stained with alizarin complexone. Age is the observed age at metamorphosis, length $(\mathrm{L} x)$ is the diameter of the otolith at age ' $x$ ' or at metamorphosis (LM), and $\Delta a, b$ is the growth ratefrom time ' $a$ ' to time ' $b$ ' $n s$ : $p>0.05, \cdot 0.01<p<0.05, \cdot 0.001<p<0.01$, $\cdots p<0.001$

\begin{tabular}{|c|c|c|c|c|c|c|c|}
\hline Tank & $\mathrm{n}$ & Age-L18 & Age-L30 & Age-L43 & Age-LM & \multicolumn{2}{|c|}{ Age(residual)-LM } \\
\hline 2 & 50 & $-0.39 \cdots$ & $-0.54 \cdots$ & $-0.62 \cdots$ & $0.16 \mathrm{~ns}$ & \multicolumn{2}{|c|}{$0.37^{\circ}$} \\
\hline 4 & 97 & $-0.51 \cdots$ & $-0.6 \cdots$ & $-0.75 \cdots$ & $0.2^{\circ}$ & \multicolumn{2}{|c|}{$0.51 \cdots$} \\
\hline 7 & 39 & $-0.58 \cdots$ & $-0.59 \cdots$ & $-0.74 \cdots$ & $0.22 \mathrm{~ns}$ & \multicolumn{2}{|c|}{$0.22 \mathrm{~ns}$} \\
\hline $7^{\mathrm{a}}$ & 38 & $-0.62 \cdots$ & $-0.72 \cdots$ & $-0.86 \cdots$ & $0.14 \mathrm{~ns}$ & \multicolumn{2}{|c|}{$0.16 \mathrm{~ns}$} \\
\hline All & 186 & $-0.41 \cdots$ & $-0.55 \cdots$ & $-0.63 \cdots$ & $0.08 \mathrm{~ns}$ & \multicolumn{2}{|c|}{$0.41 \cdots$} \\
\hline & & \multicolumn{3}{|c|}{ Length autocorrelation } & \multicolumn{3}{|c|}{ Growth rate autocorrelation } \\
\hline Tank & $\mathrm{n}$ & L18-L30 & L30-L43 & L43-LM & $\begin{array}{l}\Delta 0.18- \\
\Delta 18.30\end{array}$ & $\begin{array}{c}\Delta 18,30- \\
\Delta 30,43\end{array}$ & $\begin{array}{r}\Delta 30,43- \\
\Delta 43, \text { meta }\end{array}$ \\
\hline 2 & 50 & $0.75 \cdots$ & $0.89 \cdots$ & $0.12 \mathrm{~ns}$ & $0.11 \mathrm{~ns}$ & $0.63 \cdots$ & $0.34 \cdots$ \\
\hline 4 & 97 & $0.88 \cdots$ & $0.91 \cdots$ & $0.12 \mathrm{~ns}$ & $0.28 \cdots$ & $0.54 \cdots$ & $0.20^{\circ}$ \\
\hline 7 & 39 & $0.75 \cdots$ & $0.92 \cdots$ & $-0.03 \mathrm{~ns}$ & $0.17 \mathrm{~ns}$ & $0.7 \cdots$ & $0.4^{\circ}$ \\
\hline $7^{a}$ & 38 & $0.84^{\cdots}$ & $0.91 \cdots$ & $-0.12 \mathrm{~ns}$ & $0.21 \mathrm{~ns}$ & $0.68^{\cdots}$ & $0.36^{\circ}$ \\
\hline All & 186 & $0.81 \cdots$ & $0.91 \cdots$ & $0.19^{\circ}$ & $0.21 \cdots$ & $0.59 \cdots$ & $0.16^{\circ}$ \\
\hline
\end{tabular}

into that which is due to the growth rate up to $43 \mathrm{~d}$ and that due to the deviation (residuals) from the metamorphic age that would be predicted from that relationship. The significant positive correlation between length at metamorphosis and 'residual' age at metamorphosis in Tanks 2 and 4 (and for the data overall) (Table 6) suggests that larvae that undergo metamorphosis sooner than would be predicted from their size at $43 \mathrm{~d}$ (negative residual) do so at a size that is smaller than the overall average of $18.2 \mathrm{~mm}$. On the other hand, those larvae that took longer than expected to metamorphose were larger than average. When we combine this positive relationship between 'residual age' and metamorphic length with the negative relationship between length at $43 \mathrm{~d}$ and age at metamorphosis, the two effectively cancel each other out, leaving metamorphic age and length uncorrelated.

The predictability of metamorphic age by the body length that individuals have reached as early as $18 \mathrm{~d}$ into larval life, in addition to the observation that metamorphic age becomes increasingly predictable as larvae grow, suggests that consistency must exist in the relative size rank among individuals. Strong autocorrelations in length were detected using rank correlations (Table 6). Size at 43 d of age did not correlate strongly with length at metamorphosis as mentioned in the previous analysis. Rank correlations of growth rates from 0 to $18 \mathrm{~d}$ versus that from 18 to $30 \mathrm{~d}(\mathrm{r}=0.11$ to 0.28 ) and growth over the 18 to $30 \mathrm{~d}$ period versus that for 30 to $43 \mathrm{~d}(\mathrm{r}=0.5$ to 0.7 ) suggest that the strong size autocorrelations are only partly due to autocorrelation in growth rate (i.e. fast growers being more likely to grow quickly at later times). Therefore early growth (and the size achieved) may be important in determining how larvae rank in length relative to one another at later times.

Lastly, it should be noted that although aquaria in which larval otoliths were stained produced larvae that were on average slightly younger and larger at metamorphosis than other tanks at $11^{\circ} \mathrm{C}$ (Table 1 ), this is largely an effect of fish density (as discussed in the previous sections). Because 10 to 15 individuals were removed from these tanks during each staining period (in order to establish the SL:otolith diameter relationship), densities tend to be lower than the other tanks, and consequently growth rates a little higher.

\section{DISCUSSION}

Growth rate proved to be important in determining the timing (age and size) of metamorphosis both among and within populations of yellowtail flounder, consistent with an earlier synthesis of existing data on other species (Benoît 1999). Although temperature may determine the growth potential of larvae, affecting the location or mean of the distribution of metamorphic ages and sizes (Fig. 1), the considerable dispersion about the mean suggests that individual characters vary in a continuous manner. If this is the case, then averaging the metamorphic traits of individuals in comparisons of different rearing environments (e.g. Crawford 1984, Seikai et al. 1986, Minami \& Tanaka 1992) may mask individual level responses that vary continuously with individual growth trajectories. Below, we present evidence that this may be true.

Because individual average growth rates ( $\mathrm{mm} \mathrm{day}^{-1}$ ) are not independent of either age or length at metamorphosis, any hypothesis testing and estimates of explained variance are inappropriate, however, the slopes and intercepts of the relationships are nonetheless valid estimates (D. Schneider, Memorial University of Newfoundland, pers. comm.). Consequently the relationships between growth and age or length at metamorphosis can be compared across environments. In our study, increasing growth rates decreased the age at which individuals underwent metamorphosis (Fig. 7) and the relationship was continuous across 
temperatures and tanks, suggesting that growth rate averaged over the entire larval stage roughly determines age at metamorphosis. The effect of growth rate in determining length at metamorphosis is not as simple. Overall the length at metamorphosis increased with growth rate as did the range of lengths for a given growth rate. As growth increases, the increasing range of lengths might suggest a dependence of individual lengths on the growth rate experienced by larvae later during ontogeny, once age at metamorphosis has been roughly established (as in the present otolith study). For a given time interval prior to metamorphosis, a $10 \%$ change in growth rate will have a greater absolute impact on final size for larvae that were growing rapidly, resulting in a greater range of lengths.

Data from the otolith reconstructions further suggest that although average growth rates may roughly determine age and length at metamorphosis, precise predictions of the timing require examination of the variability in daily growth experienced by individuals over the course of their larval life. Although strong autocorrelations were detected in the sizes of larvae over time, this was only partly due to autocorrelation in growth rates. Such size autocorrelations have also
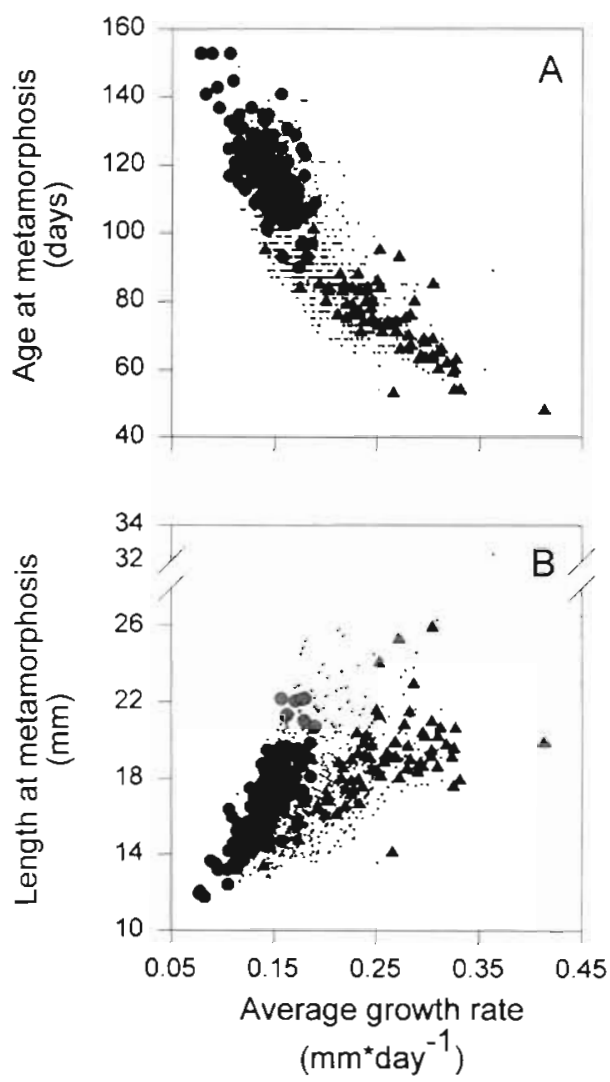

Fig. 7. Relationship between the growth rate of individual larvae, averaged over the entire larval period, and $(A)$ age, or (B) length at metamorphosis. (*) 7, (.) 11 and (4) $13^{\circ} \mathrm{C}$ been found in larval red sea bream (Umino et al. 1996), juvenile turbot Scophthalmus maximus (Rosenberg \& Haugen 1982, Imsland et al. 1996) and halibut Hippoglossus hippoglossus (Hallaråker et al. 1995). Likewise, Chambers \& Miller (1995) found similar degrees of autocorrelation in larval Atlantic menhaden Brevoortia tyrannus for similar time spans between measurements ( 10 to $15 \mathrm{~d}$ ) and also found that growth autocorrelations were weaker than those for size. The weaker rank correlations for growth rate suggest that the growth rate and the absolute size achieved early during larval life may be important in determining the timing of metamorphosis. Because the first half of larval life (particularly once feeding is initiated) may be a period in which body length increases almost exponentially (e.g. Bertram et al. 1997), this creates the potential for the establishment of difference among individuals that may persist well into the larval period.

In addition to the importance of growth rates during early ontogeny, data from the otolith diameters also suggest that the precise timing of metamorphosis depends on the growth experienced in the latter half of larval life. Individuals that underwent metamorphosis sooner than would be predicted by their growth rate up to Day 43 did so at a smaller size (the opposite being true for individuals that took longer than predicted). Unfortunately we do not have an estimate of growth rate from $43 \mathrm{~d}$ to metamorphosis that is independent of metamorphic length, precluding us from finding what determines whether an individual will metamorphose sooner/smaller or later/larger than predicted.

In addition to the results from the otolith study, the density-dependent effects observed in some of the tanks at $11^{\circ} \mathrm{C}$ may support the argument that growth later in larval life affects the timing of metamorphosis. A potential mechanism for the development of a positive correlation between age and length is that as densities in the aquaria decreased due to the removal of metamorphosed individuals, the remaining individuals experienced a decrease in competition as food was partitioned among fewer larvae (i.e. increased growth rate). The results of the otolith study suggest that these remaining individuals are the slower growing members of the population (developmentally further from metamorphosis), and thus have a longer time to utilize these benefits and grow to larger sizes. This may explain why some of the largest fish at $11^{\circ} \mathrm{C}$ were from the higher density tanks

Although the density-dependent effects observed at $11^{\circ} \mathrm{C}$ were the result of survival variability, and not intentionally included in the experiment, their occurrence has allowed us to explicitly quantify any laboratory artifacts present in our study. Although such strong density effects are unlikely in more natural situations (e.g. Fortier \& Harris 1989), by quantifying the 
effects we are able to make suggestions as to the ages and sizes at metamorphosis expected in the wild. Results from the less dense populations and from the biphasic regression analysis suggest that age and length at metamorphosis are not expected to be strongly correlated under growth rates similar to those in this study, and more natural fish densities. This result conforms with those of Benoit (1999) who found that the correlation between individual metamorphic ages and lengths improves as mean growth rate increases, but correlations become strong and positive only beyond growth rates of about $0.40 \mathrm{~mm} \mathrm{~d}^{-1}$. Considering the individual responses of age and length, we would predict that the distribution of age at metamorphosis would be positively skewed in the wild for larvae with similar growth rates as those involved in this study. Such a result was predicted by Benoît (1999) who argued that metamorphic age should be lognormally distributed. Extrapolating our results towards the lower densities expected in more natural situations we would predict that length at metamorphosis be more or less distributed normally, with a symmetric distribution.

The greatest source of error in this study is that associated with inferring ranks in body length from otolith diameters for groups of same-age larvae (i.e. using diameter as a relative index of length). This error is most true for the fish at $18 \mathrm{~d}$ of age. At such a young age (and small size), when the range of sizes within the population is small, the variance explained by the relationship between length and otolith diameter is less than at larger average sizes. This effect is partly due to measurement error, as we were limited to an accuracy of $\pm 0.5 \mu \mathrm{m}$ at a magnification of $1000 \times$, which may be significant given that measured otolith diameters at $18 \mathrm{~d}$ ranged only from 21 to $33.5 \mu \mathrm{m}$. In addition there was appreciable error between measurements made on left versus right lapilli at this age. Considered jointly, these sources of error may have weakened the relationship between back-calculated length at $18 \mathrm{~d}$ and age at metamorphosis. These sources of error would have been substantially less important for $30 \mathrm{~d}$ old larvae as the fish length/otolith diameter relationship was tighter and right and left otoliths became more similar. Umino et al. (1996) also found that the relationship relating otolith diameter and body length improved dramatically as fish grew from first feeding, where the two variables were initially uncorrelated.

The results of this study of individual variability in the timing of metamorphosis suggest that transition age and length are determined by variation in the growth rate of larvae occurring throughout early development. We begin to see the generation of variability in metamorphic traits early during ontogeny, and consequently events early on can set the stage for the rest of larval life. This is exemplified by the relationship between age at metamorphosis and the size of larvae at $18 \mathrm{~d}$. In addition to the importance of events during early ontogeny, our results suggest that variability in growth rate right up to metamorphosis may determine the precise age, and particularly the length, at metamorphosis. Overall, these cumulative growth effects may be important in determining which individuals survive past metamorphosis, and ultimately in determining recruitment variability, as metaanalyses suggest that recruitment begins to be established around that time (Bradford 1992, Bradford \& Cabana 1997). Given that metamorphic age represents the duration of the larval period (a time of high rates of mortality), and that individual metamorphic ages become roughly established early during ontogeny, the cumulative probability that an individual will survive to metamorphosis may also become established soon after hatching. The results of this study and others (Chambers et al. 1988, 1989, Bell et al. 1995, Benoit 1999) suggest that the variability among individuals in the age-at-size, size-at-age and timing of early life history transitions, along with the dependence of this variability on environmental (growth) factors, creates the potential for substantial recruitment variability under very simple assumptions regarding mortality rates (Bell 1997).

Acknowledgements. We are indebted to the staff at the Ocean Sciences Center for their advice and expertise, and for providing the eggs and sperm used in the study, as well to E. Thompson and J. Ryder for their technical assistance in the laboratory. We also thank A. R. Paradis, J. A. Brown, P. Snelgrove, $\mathrm{J}$. Rice, and 3 anonymous reviewers for helpful discussion and comments. This study was supported by a graduate fellowship from Memorial University, a scholarship from La Société Franco-Canadienne de Calgary and a Natural Science and Engineering Research Council (NSERC) post-graduate scholarship to H.P.B, as well as a NSERC research grant to P.P.

\section{LITERATURE CITED}

Anderson JT (1988) A review of size dependent survival during pre-recruit stages of fishes in relation to recruitment. J Northwest Atl Fish Sci 8:55-66

Bailey KM, Houde ED (1989) Predation on eggs and larvae of marine fishes and the recruitment problem. Adv Mar Biol $25: 1-83$

Bell KNI (1997) Complex recruitment dynamics with Dopplerlike effects caused by shifts and cycles in age-at-recruitment. Can J Fish Aquat Sci 54:1668-1681

Bell KNI, Pepin P, Brown JA (1995) Seasonal, inverse cycling of length- and age-at-recruitment in the diadromous gobies Sicydium punctatum and Sicydium antillarum in Dominica, West Indes. Can J Fish Aquat Sci 52:1535-1.545

Benoit HP (1999) Variability in the rates of growth and development in marine fishes and their effect on the timing of early life history transitions. MSc thesis, Department of Biology, Memorial University of Newfoundland, St. John's, Newfoundland 
Benoit HP, Pepin P (1999) The interaction of rearing temperature and maternal influence on egg development rates and larval size at hatch in Yellowtail flounder (Pleuronectes ferrugineus). Can J Fish Aquat Sci 56:785-794

Bertram DF, Miller TJ, Leggett WC (1997) Individual variation in growth and development during the early life stages of winter flounder, Pleuronectes americanus. Fish Bull 95: $1-10$

Beyer JE (1989) Recruitment stability and survival-simple size-specific theory with examples from the early life dynamics of marine fish. Dana 7:45-147

Bradtord MJ (1992) Precision of recruitment predictions from early life stages of marine fishes. Fish Bull 90:439-453

Bradford MJ, Cabana G (1997) Interannual variability in stage-specific survival rates and the causes of recruitment variation. In: Chambers RC, Trippel EA (eds) Early life history and recruitment in fish populations. Chapman and Hall, New York, p 469-493

Campana SE (1990) How reliable are growth back-calculations based on otoliths? Can J Fish Aquat Sci 47:2219-2227

Chambers RC, Leggett WC (1987) Size and age at metamorphosis in marine fishes: an analysis of laboratory-reared winter flounder (Pseudopleuronectes americanus) with a review of variation in other species. Can J Fish Aquat Sci 44:1936-1947

Chambers RC, Leggett WC (1989) Event analysis applied to timing in marine fish ontogeny. Can J Fish Aquat Sci 46: $1633-1641$

Chambers RC, Leggett WC (1992) Possible causes and consequences of variation in age and size at metamorphosis in flatfishes (Pleuronectiformes): an analysis at the individual, population and species levels. Neth J Sea Res 29:7-24

Chambers RC, Leggett WC (1996) Maternal influences on variation in egg sizes in temperate marine fishes. Am Zool $36: 180-196$

Chambers RC, Miller TJ (1995) Evaluating fish growth by means of otolith increment analysis: special properties of individual-level longitudinal data. In: Secor DH, Dean JM, Campana $S$ (eds) Recent developments in fish otolith research. University of South Carolina Press, Columbia, p $155-175$

Chambers RC, Leggett WC, Brown JA (1988) Variation in and among early life history traits of laboratory-reared winter flounder Pseudopleuronectes americanus. Mar Ecol Prog Ser $47: 1-15$

Chambers RC, Leggett WC, Brown JA (1989) Egg size, female effects and the correlations between early life history traits of capelin, Mallotus villosus: an appraisal at the individual level. Fish Bull 87:515-523

Cox DR, Oakes D (1984) Analysis of survival data. Chapman and Hall, London

Crawford CM (1984) Preliminary results of experiments on the rearing of tasmanian flounders, Rhombosolea tapirina and Ammotrtis rostratus. Aquaculture 42:75-81

Crowder LB, Rice JA, Miller TJ, Marshall EA (1992) Empirical and theoretical approaches to size-based interactions and recruitment variability in fishes. In: DeAngelis DL, Gross LJ (eds) Individual-based models and approaches in ecology: populations, communities and ecosystems. Chapman and Hall, New York, p 237-255

Cushing DH (1990) Plankton production and year-class strength in fish populations: an update of the match/mismatch hypothesis. Adv Mar Biol 26:249-293

Dahlberg MD (1979) A review of the survival rates of fish eggs and larvae in relation to impact assessment. Mar Fish Rev 41:1-12

Fonds M (1979) Laboratory observations on the influence of temperature and salinity on development of the eggs and growth of the larvae of Solea solea (Pisces). Mar Ecol Prog Ser 1:91-99

Fortier L, Harris RP (1989) Optimal foraging and densitydependent competition in marine fish larvae. Mar Ecol Prog Ser 51:19-33

Hallaråker HA, Folkvord A, Stefansson A (1995) Growth of juvenile halibut (Hippoglossus hippoglossus) related to temperature, day length and feeding regime. Neth J Sea Res 34:139-147

Houde F.D (1987) Fish early life dynamics and recrititineini variability. Am Fish Soc Symp 2:17-29

Houde ED (1989a) Comparative growth, mortality, and energetics of marine fish larvae: temperature and implied latitudinal effects. Fish Bull 87:471-495

Houde ED (1989b) Subtleties and episodes in the early life of fishes. J Fish Biol 35(Suppl A):29-38

Houde ED (1997) Patterns and trends in larval-stage growth and mortality of teleost fish. J Fish Biol 51(Suppl A):52-83

Imsland AK, Sunde LM, Folkvord A, Stefansson SO (1996) The interaction of temperature and fish size on growth of juvenile turbot. J Fish Biol 49:926-940

Laurence GC (1975) Laboratory growth and metabolism of the winter flounder Pseudopleuronectes americanus from hatching through metamorphosis at three temperatures. Mar Biol 32:223-229

Leggett WC, DeBlois E (1994) Recruitment in marine fishes: is it regulated by starvation and predation in the egg and larval stages? Neth J Sea Res 32:119-134

Litvak MK, Leggett WC (1992) Age and size-selective predation on larval fishes: the bigger-is-better hypothesis revisited. Mar Ecol Prog Ser 81:13-24

Minami T, Tanaka M (1992) Life history cycles in flatfish from the northwestern pacific, with particular reference to their early life histories. Neth J Sea Res 29:35-48

Pepin P (1991) Effect of temperature and size on development, mortality, and survival rates of the pelagic early life history stages of marine fish. Can J Fish Aquat Sci 48: 503-518

Pepin P. Myers RA (1991) Significance of egg and larval size to recruitment variability of temperate marine fish. Can J Fish Aquat Sci 48:1820-1828

Pepin P, Shears TH, de Lafontaine Y (1992) Significance of body size to the interaction between a larval fish Mallotus villosus and a vertebrate predator Gasterosteus aculeatus. Mar Ecol Prog Ser 81:1-12

Pepin P, Orr DC, Anderson JT (1997) Time to hatch and larval size in relation to temperature and egg size in Atlantic cod (Gadus morhua). Can J Fish Aquat Sci 54 (Suppl 1):2-10

Policansky D (1982) Influence of age, size and temperature on metamorphosis in the starry flounder, Platichthys stellatus. Can J Fish Aquat Sci 39:514-517

Reznick D, Lindbeck E, Bryga H (1989) Slower growth results in larger otoliths: an experimental test with guppies (Poecilia reticulata). Can J Fish Aquat Sci 46:108-112

Rice JA, Miller TJ, Rose KA, Crowder LB, Marschall EA, Trebitz AS, DeAngelis DL (1993) Growth rate variation and larval survival: inferences from an individual-based size-dependent predation model. Can J Fish Aquat Sci 50: 133-142

Rosenberg AA, Haugen AS (1982) Individual growth and size-selective mortality of larval turbot (Scophthalmus maximus) reared in enclosures. Mar Biol 72:73-77

Secor DH, Dean JM, Laban EH (1992) Otolith removal and preparation for microstructural examination. In: Stevenson DK, Campana SE (eds) Otolith microstructure examination and analysis. Can Spec Publ Fish Aquat Sci 117:19-57 
Seikai T, Tanangonan JB, Tanaka M (1986) Temperature influence on larval growth and metamorphosis of the Japanese flounder Palalichthys olivaceus in the laboratory. Bull Jpn Soc Sci Fish 52:977-982

Sharp GD (1987) Averaging the way to inadequate information in a varying world (editorial). Am Inst Fish Res Biol Brief 16:3-4

Sissenwine MP (1984) Why do fish populations vary? In: May RM (ed) Exploitation of marine communities. Dahlem Konferenzen. Springer-Verlag, Berlin, p 59-94

Sogard SM (1991) Interpretation of otolith microstructure in juvenile winter flounder (Pseudopleuronectes americanus):

Editorial responsibility: Otto Kinne (Editor),

Oldendorf/Luhe, Germany ontogenetic development, daily increment validation, and somatic growth relationships. Can $J$ Fish Aquat Sci 48: $1862-1871$

Szedimayer ST, Able KW (1992) Validation studies of daily increment formation for larval and juvenile summer flounder, Paralichthys dentatus. Can J Fish Aquat Sci 49: $1856-1862$

Umino T, Takeda T, Nakagawa H (1996) Estimation of growth pattern based on otolith-tagging in the early life stage of reared red sea bream. Fish Sci 62:142-143

Wilkinson L (1992) SYSTAT the system for statistics. SYSTAT Inc, Evanston, IL

Submitted: January 12, 1999; Accepted: April 12, 1999 Proofs received from author(s): July 20,1999 